\title{
Mycobacteriosis in peafowl: Analysis of four cases
}

\author{
ALEKSANDRA LEDWOŃ, EWA AUGUSTYNOWICZ-KOPEĆ*, \\ PAWEŁ PARNIEWSKI**, JOANNA BONECKA***, MAGDALENA OSTRZESZEWICZ***, \\ BEATA DOLKA, PIOTR SZELESZCZUK
}

\author{
Department of Pathology and Veterinary Diagnostics, Faculty of Veterinary Medicine, \\ Warsaw University of Life Sciences, Nowoursynowska 159c, 02-776 Warsaw \\ *Department of Microbiology, National Tuberculosis and Lung Diseases Research Institute, Płocka 26, 01-138 Warsaw \\ **Institute of Medical Biology of PAS, ul. Lodowa 106, 93-232 Łódź \\ ***Department of Small Animal Diseases with Clinic, Faculty of Veterinary Medicine, \\ Warsaw University of Life Sciences, Nowoursynowska 159c, 02-776 Warsaw
}

Ledwoń A., Augustynowicz-Kopeć E., Parniewski P., Bonecka J., Ostrzeszewicz M., Dolka B., Szeleszczuk P. Mycobacteriosis in peafowl: Analysis of four cases

Summary

Peafowl (Pavo cristatus), similarly to other Galliformes, are particularly susceptible to infection by Mycobacterium avium. Peafowl differ from other Galliformes in the clinical image of the infection, with dominating respiratory signs. Occurrence of severe and sustained dyspnoea in peafowl raises suspicion of mycobacteriosis, which, however, is not always easy to confirm. In the cases described here, mycobacteria were detected in direct swabs from the trachea of two individuals, and cultures were conducted on the LöwensteinJensen medium. In one individual, no mycobacteria were found in tracheal swabs stained by the Ziehl-Neelsen method, despite the presence of clear clinical signs. The fourth case was a young bird submitted for necropsy. The cause of death was a mechanical trauma, but scarce caseous nodules typical of mycobacteriosis were found in the liver, spleen and lungs. The Mycobacterium avium isolates obtained from those cases were compared using (CCG)4-based PCR. A high similarity of three isolates of Mycobacterium avium subsp. avium was observed, two of which were derived from peafowl originating from the same farm, while the isolate from the fourth bird differed significantly and was identified by sequencing as Mycobacterium avium subsp. paratuberculosis.

Keywords: peafowl, Mycobacterium avium, mycobacteriosis

Mycobacterioses of birds, also known as avian tuberculosis, are a long-known problem often occurring in Galliformes (13). In modern large-scale poultry farms, where birds are kept for a period of several to several dozen weeks, and the bedding is replaced after the end of each production cycle, mycobacterioses are extremely rare (29). However, the problem of mycobacterioses is still present mainly in free-range poultry, as well as in zoos and parks, where the birds have contact with soil contaminated with faeces, which can be a source of mycobacterial infections for many years ( 7 , $14,18,21)$. Although ill birds are eliminated in reasonably managed parks and zoos, individual owners are often very attached to their animals and do not consent to euthanize the sick bird, but ask for treatment $(4,26)$. Unfortunately, treatment of mycobacterioses is long and costly, and its outcomes are uncertain $(15,24$, 26). Bacteria belonging to the Mycobacterium avium complex (MAC) are intrinsically resistant to many antibiotics and antituberculosis drugs (30).
There is also the risk that the bacteria may acquire drug resistance during treatment (5). The potential threat to the health of other animals and humans is also of considerable importance $(13,27,30)$. To date, the authors have diagnosed three cases of peafowl (Pavo cristatus) mycobacteriosis caused by Mycobacterium avium subsp. avium and one caused by Mycobacterium avium subsp. paratuberculosis, which is also pathogenic for birds $(2,20)$.

\section{Material and methods}

Birds examined. The material for the study were three live birds and one dead bird obtained at different times. The first bird (Peacock 1) was a five-year-old that had shown intensifying signs of dyspnoea, also at rest, and severely decreased appetite for approximately one month. The second case (Peahen 2) was a three-year-old with severe dyspnoea. During the procedure of obtaining a swab specimen from the trachea, the peahen expectorated approximately $2 \mathrm{ml}$ of thick, mucous fluid that was subsequently tested for the 
Tab. 1. Characteristics of the disease in the peafowl examined

\begin{tabular}{|c|c|c|c|c|c|c|c|}
\hline $\begin{array}{c}\text { Peafowl } \\
\text { no. }\end{array}$ & Sex & $\begin{array}{c}\text { Age } \\
\text { (years) }\end{array}$ & $\begin{array}{l}\text { Dyspnoea } \\
\text { signs }\end{array}$ & $\begin{array}{l}\text { Presence of mycobacteria } \\
\text { in the tracheal swab stained } \\
\text { by the Ziehl-Neelsen method }\end{array}$ & $\begin{array}{l}\text { Positive result of the } \\
\text { tracheal swab/sample } \\
\text { culture }\end{array}$ & $\begin{array}{l}\text { Presence of lesions } \\
\text { in the trachea }\end{array}$ & $\begin{array}{l}\text { Positive result of the } \\
\text { internal organ cultures }\end{array}$ \\
\hline 1 & $\hat{\sigma}$ & 5 & + & + & + & nt* $^{*}$ & $\mathrm{nt}$ \\
\hline 2 & q & 3 & + & - & + & nt & nt \\
\hline 3 & $\hat{\sigma}$ & 2 & + & - & - & + & + \\
\hline 5 & q & $<1$ & - & nt & nt & - & + \\
\hline
\end{tabular}

Explanation: $\mathrm{nt}$ - not tested

presence of Mycobacterium. The third case (Peacock 3) was a two-year-old originating from the same farm as Peahen 2 and was brought to the clinic 1.5 years after the death of the female. Its clinical signs were identical to those in the two previous cases. The fourth case (Peahen 4), submitted for necropsy, was under the age of 1 year. A sudden death due to a trauma was determined in that bird.

Initial therapy. Initially, symptomatic treatment was applied, consisting in subcutaneous administration of fluids (glucose $5 \%+$ sol. Ringeri Lactate + Duphalyte), enrofloxacin $(20 \mathrm{mg} / \mathrm{kg}$ bw per day: Pefowls 1 and 2$)$ or marbofloxacin $(10 \mathrm{mg} / \mathrm{kg}$ bw per day: Peacock 3$)$.

Diagnostic imaging. X-ray examination and tracheoscopy were conducted in Peacock 3. For general anaesthesia, butorphanol (Butomidor, Rihter Pharma AG) at $0.5 \mathrm{mg} / \mathrm{kg}$ bw i.m., and isoflurane (Aerrane, Baxter) at $5 \%$ for induction and $2 \%$ for maintenance, were used. An endoscopic trachea examination was conducted using a rigid endoscope NOPA XP 700/33. X-ray examination was conducted in Peacock 3 in lateral and dorso-ventral positions.

Sampling material for tests. Tracheal swabs were collected from all three live birds for a bacteriological test for mycobacteria, and faecal matter was collected for a parasitological test and bacterioscopy (Ziehl-Neelsen stain).

Peacock 3 was euthanised, and fragments of its organs (lungs, liver and spleen) were collected during necropsy. From the dead Peahen 4, fragments of caseous nodules located in the lungs and liver were sampled.

Specimen staining and cultures. Specimens stained by the Ziehl-Neelsen method were derived from tracheal swabs and organ impressions from Peacock 3 and Peahen 4. Tracheal swabs from Peafowl 1-3 and organ samples (lung, liver) from Peafowl 3 and 4 were cultured on the Löwenstein-Jensen PACT medium (BD, USA). Moreover, a tracheal swab from Peacock 1 and fragments of the lung and liver collected during necropsy from Peacock 3 were cultured on the BBL MIGIT medium in the BD BACTEC ${ }^{\text {TM }}$ MGIT 960 system.

DNA isolation and PCR amplification techniques and clustering analyses. (CCG)4-based PCR for genotyping $M$. avium was performed according to the methodology described by Wojtasik et al. (34).

PCR amplification techniques. An amplification reaction for (CCG)4-based PCR using 50-N6(CCG)4 primers $(\mathrm{N}=\mathrm{A}, \mathrm{T}, \mathrm{C}$, or $\mathrm{G})$ and gel electrophoresis was also performed according to a strict procedure described elsewhere $(33,34)$. The DNA products for (CCG)4-based primers ranged from 0.1 to $2.5 \mathrm{kbp}$. All gels were stained with ethidium bromide $\left(1 \mathrm{lg} \mathrm{ml}^{-1}\right)$, visualized on a UV-transilluminator and photographed (Fc8800, Alphainnotech).
Clustering analyses. (CCG)4-based PCR fingerprinting images were processed for further analysis with the BioNumerics software. The sizes of PCR products in each lane of agarose gels were normalized in reference to a $100-b p$ DNA size marker (Perfect 100-bp DNA ladder, EURX Ltd.) containing 13 fragments that ranged in size from 100 to $1,000 \mathrm{bp}$ in 100-bp increments and additional fragments of $1.5,2$, and $2.5 \mathrm{kbp}$. Clustering analysis of the (CCG)4-based PCR band patterns was conducted with the BioNumerics software version 5.00 (Applied Maths), and a dendrogram was generated by the Unweighted-Pair Group Method (UPGMA) using average linkages Pearson's coefficient. For differentiation analyses, the discriminatory index (DI) (10) was evaluated.

\section{Results and discussion}

Clinical examinations. In the three peafowl examined clinically, identical signs of dyspnoea (Fig. 1) and decreased appetite were observed. The general condition of the animals improved after treatment. Five months after the end of the two-and-a-half-month treatment of Peacock 1, the owner reported re-occurrence of dyspnoea signs, and despite his insistence on undertaking treatment again, euthanasia was recommended. Unfortunately, the owner did not submit the animal for necropsy.

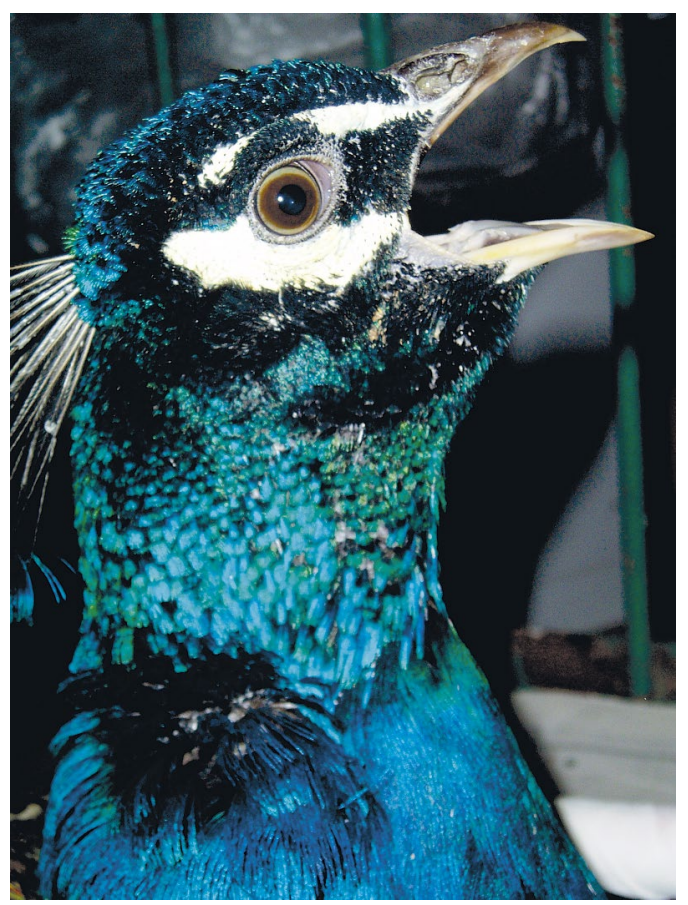

Fig. 1. Signs of severe dyspnoea in Peacock 1 

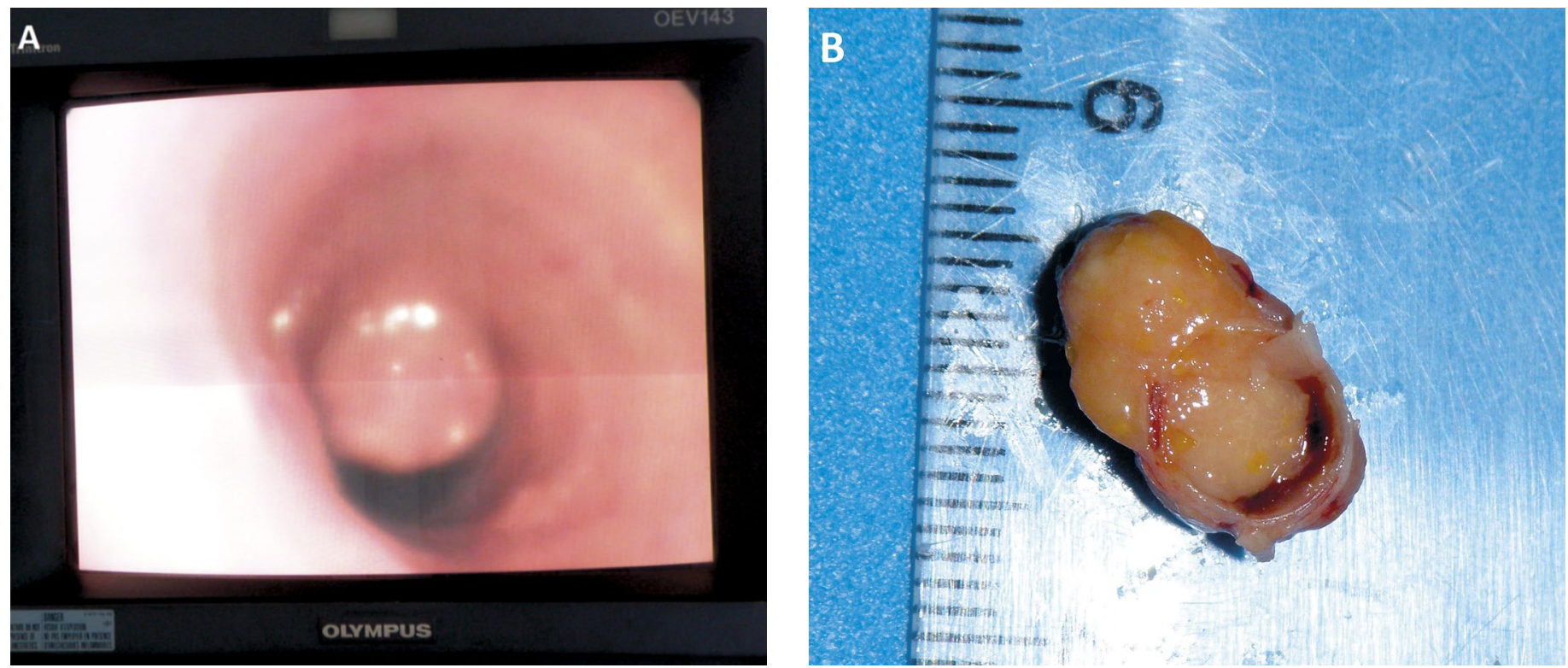

Fig. 2. A) Endoscopy: a nodule blocking the tracheal lumen; B) Necropsy: the same lesion visualised in a transverse section of the trachea. The granuloma also covers the external part of the trachea

Treatment following diagnosis. In Peacock 1, in which an invasion by Syngamus trachea was also detected, ivermectin (Ivomec, Merial, France) at a dose of $200 \mathrm{ug} / \mathrm{kg}$ bw was administered i.m. After obtaining a positive result of tracheal swab culture, a targeted antimycobacterial treatment was undertaken. Enrofloxacin (Vetoflok, PLIVA Krakow) at a dose of $15 \mathrm{mg}$ every 12 hours i.m. and clarithromycin (Klacid, Abbott, France) at a dose of $30 \mathrm{mg} / \mathrm{kg}$ bw every 12 hours p.o. were used, along with inhalations of enilkonazole (Imaverol, Jansen, Belgium), 2\% solution in physiological saline, 25 min, 2 times a day.

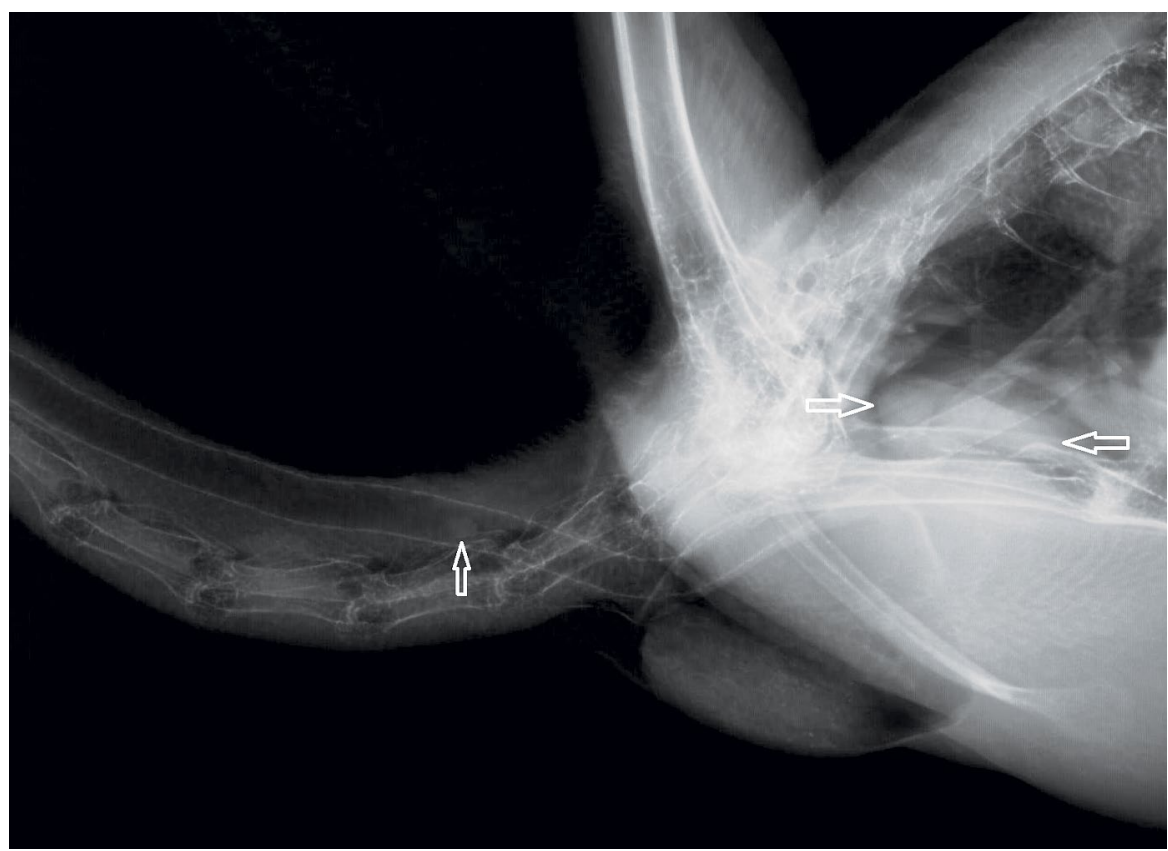

Fig. 3. X-ray of the cervical section of the trachea and the mediastinum. In the projection of the trachea, a minor opacity of an intensity typical of soft tissues, while in the mediastinum above the coracoid line, a mass of $3 \mathrm{~cm} \times 1.5 \mathrm{~cm}$ was found
Resting dyspnoea resolved after 10 days of treatment, while stress-associated dyspnoea (during immobilisation) resolved after the following 3 weeks. Throughout treatment, the peacock demonstrated decreased or selective appetite.

In all peafowl examined, improvement was obtained after supportive and antibiotic therapy. In Peahen 2, death occurred after approximately 3 weeks, but the enrofloxacin treatment lasted only 1 week. Peacock 3 lived for approximately 1 month after the first examination and received marbofloxacin throughout that period, which induced a short-term improvement. The owners submitted the animal for further diagnostics after that time had passed. The results of additional examinations (X-ray and endoscopy) were the basis for euthanasia.

Diagnostic imaging. Diagnostic imaging was conducted only in Peacock 3 . In the lower section of the trachea of Peacock 3 , a nodule blocking $3 / 4$ of the tracheal lumen was detected (Fig. 2). The nodule was visible in $\mathrm{X}$-ray images (Fig. 3). Moreover, $\mathrm{X}$-ray revealed an opaque mass of $3 \mathrm{~cm} \times 1.5 \mathrm{~cm}$ in the mediastinum (Fig. 3) and a mass of approx. $4 \mathrm{~cm}$ in diameter in the posterior part of the lung (Fig. 4). In the body cavity, enlargement of the spleen to $5 \mathrm{~cm}$ $\times 2.5 \mathrm{~cm}$ was observed (Fig. 4).

Microscopic examination. In the microscopic specimen of faeces from Peacock 1 stained by the ZiehlNeelsen method, a moderate number of acid-fast bacteria were found. 


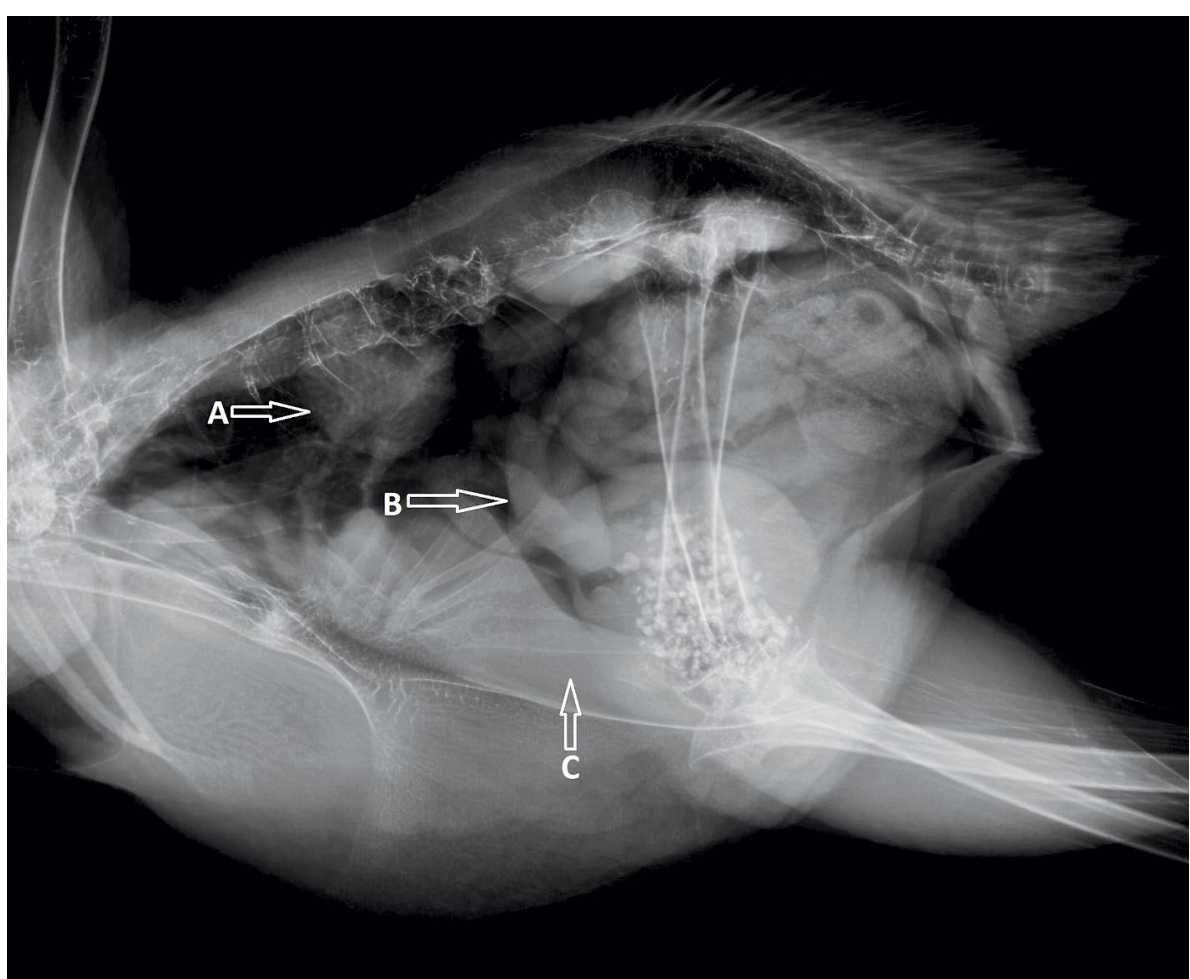

Fig. 4. X-ray of the thoracic and abdominal organs. An opaque area of significant size - a mass in the projection of the lung (A). Apart from the focal lesion, the lungs were well aerated, without visible changes. Magnified opacity of the spleen (B) and liver (C)

Percentage of similarity

CCG-PCR profile

0

$\begin{array}{lllll}20 & 40 & 60 & 80 & 100\end{array}$

\begin{tabular}{|c|c|}
\hline & 90.7 \\
\hline 38.2 & 95.1 \\
\hline
\end{tabular}

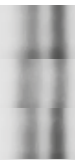

Fig. 5. Analysis of similarities between the four isolates of Mycobacterium avium from the described cases of mycobacteriosis in peafowl

In Peafowl 2 and 3, no acid-fast bacteria were found either in the tracheal swab or in the faeces specimen.

Microbiological examination. In Peacock 1, a positive result was obtained for the direct sample from the tracheal swab, and growth of Mycobacterium avium subsp. avium was observed on culture media, both before treatment and after three weeks of treatment. However, negative results for swabs were obtained two weeks and two months after the end of treatment. In the case of Peahen 2, mycobacterial growth on the Löwenstein-Jensen medium was obtained. The tracheal swabs taken from Peacock 3 did not yield positive results in the bacterioscopic examination and growth on the Löwenstein-Jensen medium. Growth of Mycobacterium avium subsp. avium from this individual was obtained only in cultures of the lung and the liver. With regard to the necropsy material from Peacock 4, a positive result was obtained for culture and bacterioscopy.

DNA isolation and PCR amplification techniques and clustering analyses. The highest similarity was
P1

P2

P3

P4

demonstrated by examining the strains of Mycobacterium avium subsp. avium from Peahen 2 and Peacock 3 originating from the same farm. The similarity of the strain derived from Peacock 1 was high as well. However, the Mycobacterium avium subsp. paratuberculosis strain isolated from Peahen 4 had only approx. 38\% similarity with the other isolates (Fig. 5).

In peafowl, signs of severe dyspnoea not associated with mycobacteriosis can be caused by aspergillosis and other bacterial (mycoplasmosis) and viral infections, as well as by advanced syngamosis and presence of foreign bodies $(25,27,28)$. It is also possible to isolate several pathogens in one case (21). Signs identical to those of mycobacteriosis have been seen by the authors in peafowl with avian pox with respiratory involvement or caseous lesions in the posterior larynx (Syrinx), from which Enterobacter sp. was isolated. The difference in the clinical course of respiratory avian pox and mycobacteriosis was the more rapid development of the former and a larger number of concurrently affected animals. In the case of Enterobacter infection, despite clinical signs identical to those in Peahen 2, no typical lesions were found in X-ray examination. As can be inferred from the cases described, mycobacteriosis cannot always be reliably diagnosed in live birds, even those with advanced clinical signs. In the intravital diagnostics of mycobacterioses, it is particularly useful to take biopsies directly from the affected organ during an endoscopic examination (8). However, in a study by Saggese et al., a positive result of a biopsy was obtained in only 3 out of 16 infected birds (26).

No information on the treatment of mycobacterioses in Galliformes has been found in the available literature. Suspected birds, e.g., those showing a positive tuberculin sensitivity test, were eliminated from the farm (3). Vaccines against mycobacterioses have been developed and show a good effectiveness, but are not marketed $(6,16)$. Treatment has been attempted in domestic birds, including collared doves and parrots $(14,26)$. It is recommended to isolate treated birds from the flock for at least 2 years and to conduct bacteriological examinations every 6 to 12 weeks (23). Effective treatment of mycobacterioses has been conducted in accompanying animals, such as cats, 
dogs and ferrets $(1,10,17,19,22,31,32)$. However, treatment of mycobacterioses is conducted mainly in humans. AIDS patients are a group in whom mycobacterioses are the most serious problem. In humans, treatment with two or three medicines should last up to 12 months (12). Treatment of mycobacterioses in ornamental birds of the Galliformes genus is possible, but even a 4-month therapy may be insufficient (14, $24)$. On the other hand, a 6-month therapy can produce satisfactory results (26). Some authors recommend that treatment of mycobacterioses in birds should be continued for as much as 1 year. As demonstrated by case reports, treatment in other accompanying animals usually lasted from several weeks to over a year $(1,5$, 11, 31). Animals treated for mycobacterioses would often die after or during treatment for reasons other than the infectious disease (17).

In practice, administering drugs over such a long period and maintaining an appropriate sanitary regime requires discipline and responsibility on the side of animal carers. Irregular administration of drugs may lead to the onset of bacterial resistance. Resolution of clinical signs, as in the case of Peacock 1, does not guarantee that the disease has been cured. Therefore, we do not recommend leaving treatment to an owner who may not be aware of the responsibility and risk.

\section{References}

1. Baral R. M., Metcalfe S. S., Krockenberger M. B., Catt M. J., Barrs V. R., Mc Whirter C., Hutson C. A., Wigney D. I., Martin P., Chen S. C., Mitchell D. H., Malik R. J.: Disseminated Mycobacterium avium infection in young cats: overrepresentation of Abyssinian cats. Feline Med. Surg. 2006, 8, 23-44.

2.Beard P. M., Daniels M. J., Henderson D., Pirie A., Rudge, K., Buxton D., Rhind S., Greig A., Hutchings M. R., Mckendrick I., Stevenson K., Sharp J. M.: Paratuberculosis infection of nonruminant wildlife in Scotland. J. Clin. Microbiol. 2001, 39, 1517-1521.

3. Behlert O., Gerlach H.: Hygienic measures against avian mycobacteriosis in the pheasantry of the Cologne Zoo. Berl. Munch. Tierarztl. Wochenschr. 1991, 104, 12-15.

4. Buur J., Saggese M. D.: Taking a rational approach in the treatment of avian mycobacteriosis.: Vet. Clin. North. Am. Exot. Anim. Pract. 2012, 1, 57-70.

5. Dietrich U., Arnold P., Guscetti F., Pfyffer G. E., Spiess B.: Ocular manifestation of disseminated Mycobacterium simiae infection in a cat.: J. Small Anim. Pract. 2003, 44, 121-125.

6. Falkinham J. O.: Ecology of nontuberculous mycobacteria: Where do human infections come from? Semin. Respir. Crit. Care Med. 2013, 34, 95-102.

7. Falkinham J. O., Gross W. B., Pierson F. W.: Effect of different cell fractions of Mycobacterium avium and vaccination regimens on Mycobacterium avium infection. Scand. J. Immunol. 2004, 59, 478-484.

8. Foldenauer U., Curd S., Zulauf I., Hatt J. M.: Ante mortem diagnosis of mycobacterial infection by liver biopsy in a budgerigar (Melopsittacus undulatus). Schweiz. Arch. Tierheilkd. 2007, 149, 273-276.

9. Hunter P. R., Gaston M. A.: Numerical index of the discriminatory ability of typing systems: an application of Simpson's index of diversity. J Clin. Microbiol. 1988, 26, 2465-2466.

10. Kaufman A. C., Greene C. E., Rakich P. M., Weigner D. D.: Treatment of localized Mycobacterium avium complex infection with clofazimine and doxycycline in a cat. J. Am. Vet. Med. Assoc. 1995, 207, 457-459.

11. Kiehn T. E., Hoefer H., Böttger E. C., Ross R., Wong M., Edwards F., Antinoff $N$., Armstrong D.: Mycobacterium genavense infections in pet animals. J. Clin. Microbiol. 1996, 34, 1840-1842.

12. Koirala J., Harley W. B.: Mycobacterium avium intracellulare. eMedicine J. 2006, 2 (12).http://www.emedicine.com/med/topic1532.htm
13. Kriz P., Kaevska M., Bartejsova I., Pavlik I.: Mycobacterium avium subsp. avium found in raptors exposed to infected domestic fowl. Avian Dis. 2013, 57, 688-689.

14.Ledwoń A., Dolka I., Dolka B., Cegiełkowska M., Czopowicz M., Szeleszczuk P.: Multidrug therapy of Mycobacterium avium subsp. avium infection in experimentally inoculated budgerigars (Melopsittacus undulatus). Avian Pathol. 2015, 44, 470-474.

15.Ledwoń A., Szeleszczuk P., Zwolska Z., Augustynowicz-Kopeć E., Kozak M.: Occurrence of Mycobacterium in the faeces of parrots kept in zoological gardens and private aviaries in Poland. Bull. Vet. Inst. Pulawy 2008, 52, 341-346.

16. Lipiec M.: Ocena właściwości uodparniających doświadczalnych szczepionek przeciwko gruźlicy kur. PhD Thesis, Puławy 1992.

17. Lucas J., Lucas A., Furber H., James G., Hughes M. S., Martin P., Chen S. C., Mitchell D. H., Love D. N., Malik R.: Mycobacterium genavense infection in two aged ferrets with conjunctival lesions. Aust. Vet. J. 2000, 78, 685-689.

18. Maekawa K., Ito Y., Hirai T., Kubo T., Imai S., Tatsumi S., Fujita K., Takakura S., Niimi A., Iinuma Y., Ichiyama S., Togashi K., Mishima M.: Environmental risk factors for pulmonary Mycobacterium avium-intracellulare complex disease. Chest. 2011, 140, 723-729.

19. Miller M. A., Greene C. E., Brix A. E.: Disseminated Mycobacterium aviumintracellulare complex infection in a miniature schnauzer. J. Am. Anim. Hosp. Assoc. 1995, 31, 213-216.

20. Miranda A., Pires M. A., Pinto M. L., Sousa L., Sargo R., Rodrigues J., Coelho A. C., Matos M., Coelho A. M.: Mycobacterium avium subspecies paratuberculosis in a diamant sparrow. Vet. Rec. 2009, 165, 184.

21. Nemeth N. M., Gonzalez-Astudillo V., Oesterle P. T., Howerth E. W.: A 5-Year Retrospective Review of Avian Diseases Diagnosed at the Department of Pathology, University of Georgia. J. Comp. Pathol. 2016, 155, 105-120.

22. Paulsen D. B., Kern M. R., Weigand C. M.: Mycobacterial neuritis in a cat. J. Am. Vet. Med. Assoc. 2000, 216, 1589-1591.

23. Pesek L.: Avian Tuberculosis (Mycobacteriosis). Bird to Human Transmission Zoonotic Diseases - Part III Winged Wisdom, Pet Bird Magazine. 1998, http:// www.birdsnways.com/wisdom/ww25eiii.htm

24. Pollock C. G.: Implications of Mycobacteria in Clinical Disorders, [in:] Harrison G. Lightfoot L.: Clinical Avian Medicine, Spix Publishing. Palm Beach, FL, USA 2006, p. 681-690.

25. Rettenmund C. L., Chen S.: Tracheal obstruction due to glossal entrapment by a string foreign body in a peahen (Pavo cristatus). J. Exot. Pet Med. 2013, 22, 200-205.

26. Saggese M. D., Tizard I., Gray P., Phalen D. N.: Evaluation of Multidrug Therapy With Azithromycin, Rifampin, and Ethambutol for the Treatment of Mycobacterium avium subsp. avium in Ring-neck Doves (Streptopelia risoria): An Uncontrolled Clinical Study. J. Avian Med. and Surg. 2014, 28, 280-289.

27. Salicio Y., Álvaro A. I., Bermejo A. I., Navascués A., Ojer M., Ruz A., Dorronsoro I.: An clinical relevance of nontuberculous Mycobacteria. Sist. Sanit. Navar. 2008, 31, 33-42.

28. Shankar B. P.: Common Respiratory Diseases of Poultry. Vet. World. 2008, 1, 217-219.

29. Shivaprasad H. L., Palmieri C.: Pathology of mycobacteriosis in birds. Vet. Clin. North. Am. Exot. Anim. Pract. 2012, 15, 41-55.

30. Slany M., Ulmann V., Slana I.: Avian Mycobacteriosis: Still Existing Threat to Humans. Biomed. Res. Int. 2016: 4387461. doi: 10.1155/2016/4387461.

31. Studdert V. P., Hughes K. L.: Treatment of opportunistic mycobacterial infections with enrofloxacin in cats. J. Am. Vet. Med. Assoc. 1992, 201, 1388-1390.

32. Thorel M. F., Huchzermeyer H. F., Michel A. L.: Mycobacterium avium and Mycobacterium intracellulare infection in mammals. Rev. Sci. Tech. 2001, 20, 204-218.

33. Wojtasik A., Kubiak A. B., Krzyżanowska, A., Majchrzak, M., AugustynowiczKopec E., Parniewski P.: Comparison of the (CCG) -based PCR and MIRUVNTR for molecular typing of Mycobacterium avium strains. Mol. Biol. Rep. 2012, 39, 7681-7686.

34. Wojtasik A., Majchrzak M., Adamus-Bialek W., Augustynowicz-Kopec E., Zwolska Z., Dziadek J., Parniewski P.: Trinucleotide repeat sequence-based $\mathrm{PCR}$ as a potential approach for genotyping Mycobacterium gordonae strains. J. Microbiol. Methods 2011, 85, 28-32.

Corresponding author: Aleksandra Ledwoń DVM, PhD, ul. Ciszewskiego 8/065, 02-787 Warszawa; e-mail: aledwonn@yahoo.pl 